\title{
Stereotactic lung reirradiation for local relapse: A case series
}

\author{
Rémy Kinj $^{\mathrm{a}, *}$, Alessio Casutt ${ }^{\mathrm{b}}$, Alexander Bennassi ${ }^{\mathrm{a}}$, Hasna Bouchaab ${ }^{\mathrm{c}}$, Véronique Vallet ${ }^{\mathrm{d}}$, \\ Alban Lovis ${ }^{\mathrm{b}}$, Mahmut Ozsahin ${ }^{\mathrm{a}}$ \\ ${ }^{a}$ Department of Radiation Oncology, Lausanne University Hospital and University of Lausanne, Lausanne, Switzerland \\ ${ }^{\mathrm{b}}$ Department of Pulmonology, Lausanne University Hospital, Lausanne, Switzerland \\ ${ }^{\mathrm{c}}$ Department of Medical Oncology, Lausanne University Hospital and University of Lausanne, Lausanne, Switzerland \\ ${ }^{\mathrm{d}}$ Institute of Radiation Physics, Lausanne University Hospital and University of Lausanne, Lausanne, Switzerland
}

\section{A R T I C L E I N F O}

\section{Article history:}

Received 18 February 2021

Revised 17 March 2021

Accepted 28 March 2021

Available online 5 April 2021

\section{Keywords:}

Lung reirradiation

SBRT reirradiation

Stereotactic treatment

Lung cancer

\begin{abstract}
A B S T R A C T
Introduction: Local recurrence after lung SBRT for early stage NSCLC is rare but its treatment remains a challenge due to limited surgical options. We report a case series of 5 patients treated by stereotactic lung salvage reirradiation for local relapse after a previous lung SBRT.

Material and methods: Included patients presented an isolated primary lung relapse within at least the $50 \%$ isodose of the previous SBRT treatment. Typical reirradiation schedule was $60 \mathrm{~Gy}$ in 8 fractions at isodose $80 \%$ and was delivered by Cyberknife ${ }^{\circledR}$ using Synchrony ${ }^{\circledR}$ fiducial tracking system. Dose summations were performed to evaluate the safety of the reirradiation.

Results: We identified 5 patients presenting peripheral lesions. All reirradiated lesions were locally controlled after a median follow-up of 11.1 months $(6,7-12,2)$, while PFS at 6 months was $60 \%(n=3)$. We did not notice any Grade 3 or more acute or late adverse event.

Conclusion: We observed encouraging short-term outcome of lung SBRT reirradiation in patients presenting isolated local relapse of an early-stage NSCLC. Further studies are necessary to confirm the safety and efficiency of this salvage treatment approach.

(c) 2021 The Authors. Published by Elsevier B.V. on behalf of European Society for Radiotherapy and Oncology. This is an open access article under the CC BY license (http://creativecommons.org/licenses/by/
\end{abstract}

4.0/).

\section{Introduction}

Stereotactic body radiotherapy (SBRT) is a well-established treatment option for patients presenting an early-stage nonsmall cell lung cancer (NSCLC). The main failure pattern after lung SBRT is represented by distant failure. Local recurrence in a previously irradiated lung volume is observed in 5 to $15 \%$ of cases and treatment remains a challenge due to co-morbidities limiting surgical options [1]. Retreatment with conventional fractionated radiotherapy (CFRT) can be consider as a salvage option but remains poor outcomes [2]. Few studies explored salvage SBRT for reirradiation after a first course of lung SBRT, more experiences must be described to determine control and toxicity rates. We recently considered the opportunity to repeat lung SBRT. Here we report a case series of 5 patients treated by stereotactic lung salvage reirradiation for local relapse after a previous lung SBRT.

\footnotetext{
* Corresponding author.

E-mail address: remy.kinj@chuv.ch (R. Kinj).
}

\section{Material and methods}

From November 2019, during our clinical follow-up, we identified patients who presented localized lung relapses in a previously irradiated volume by SBRT. We included in this report patients presenting an isolated primary lung relapse within at least the 50\% isodose of the previous SBRT treatment. The decision to reirradiate was approved by the local multidisciplinary thoracic tumor board, and patients were not considered eligible for salvage surgery due to co-morbidities. All patients benefited from reirradiation after fiducial marker (FM) placement and was performed by Cyberknife ${ }^{\circledR}$ using Synchrony ${ }^{\circledR}$ fiducial tracking system (Accuray, Sunnyvale). Typical reirradiation schedule was $60 \mathrm{~Gy}$ in 8 fractions at isodose $80 \%$ corresponding to a Biological Effective Dose for $\alpha / \beta 10 \mathrm{~Gy}$ (BED10) of $105 \mathrm{~Gy}$. We performed deformable registration on Raystation ${ }^{\circledR}$ (Raysearch, Stockholm) treatment planning system, then plans were summed in order to evaluate the safety of the reirradiation treatment. Cumulative dosimetry had to respect the constraints of a 5 fractions plan for organs at risk according to American Association of Physicists in Medicine doses constraints [3]. Cumulative dosimetry had particularly to respect firstly spinal 
canal constraints (V23 $<0.03 \mathrm{cc}$ ), secondly and lungs tissues constraints V5 < 65\%,and finally both V12.5 < $1500 \mathrm{cc}, \mathrm{V} 13.5<1000 \mathrm{cc}$. There was no maximal dose limit in lungs while maximal dose had to be localized in the PTV of the reirradiated target.

\section{Results}

We identified 5 patients, 3 out of 5 relapses were histologically proven, and the remaining two were assessed by their clinical evolution followed by iterative morphological and metabolic imaging.

The median age of patients at relapse was 78.9 years (range, 62.6-88.8) and relapse was diagnosed with a median time lapse of 31.3 months (range, 15.4-91.6) after the first SBRT. First SBRT median dose was $55 \mathrm{~Gy}(45-60)$ in 5 fractions [3-8]. Most of first lung cancers (4/5) were classified as CT1NOM0 (8th TNM classification). The remaining last patient was firstly irradiated for an isolated lung relapse of a lung adenocarcinoma previously (20 months before the radiation therapy) treated by surgical resection.

The mean lung dose (MLD) of the reirradiation was $1.9 \mathrm{~Gy}$ (range, 1.0-2.0), the volume of lungs receiving $5 \mathrm{~Gy}$ (V5) was 7.5\% (range, 4.9-9.5) and V20 1\% (range, 0.8-3.9). All reirradiated lesions were peripherally located and the median Planning Target Volume (PTV) was $4.0 \mathrm{~mL}$.

Three patients previously received Cyberknife ${ }^{\circledR}$ treatment with fiducial tracking, one patient had Tomotherapy ${ }^{\circledR}$ SBRT, and one had a VMAT SBRT treatment.

After reirradiation, cumulative MLD was 5.1 Gy (range, 3.6-7.8) and cumulative V5 was 28.5 Gy (range, 16.0-48.5). Median maximal cumulated PTV dose was 90.8 Gy (range, 76.2-135.8) (Table 1).

All reirradiated lesions were locally controlled after a median follow-up of 11.1 months (6,7-12,2), while PFS at 6 months was $60 \%(n=3)$. One patient presented at 6 months a contralateral new lung lesion successively treated by SBRT. Another patient developed a single brain metastasis that was surged and irradiated. We did not notice any Grade 3 or more acute or late adverse event (Common Terminology Criteria for Adverse Events version 4) [4]. Most frequent adverse event was acute Grade 1 asthenia in 2 patients.

\section{Discussion}

We report our early clinical outcome after lung SBRT reirradiation. It may represents a new salvage option for these nonoperable patients with significant co-morbidities.

The singularity of our data is that we report a series of patients who underwent two sequences of lung high-dose SBRT closely located. Most of publications concerning SBRT reirradiation for local relapse usually report data after a single or two conventionally-fractionated course/s. These experiences revealed acceptable local control rate with relatively high rates of lung tox- icity such as radiation induced pneumonitis [5-9]. Synchrony ${ }^{\circledR}$ tracking system uses a 3-D co-ordinate system that tracks the target during the respiratory cycle by means of previously inserted metallic FM. The tracking system permits the maximal reduction of margins conducing to a better sparing of healthy lung tissue. As reirradiation volume always correlates with toxicity outcome in the reirradiation setting, our accurate SBRT technique permits a better toxicity outcome. Moreover we choosed a fractionated regimen in 8 fractions (usually used for ultra-central lesions) in order to enhance tolerance of treatment while persevering biological efficiency ((BED10) of 105 Gy).

Kennedy et al. also used accurate SBRT technique in a comparable study population. Their experience represents the largest cohort with 21 included patients. They remained a low rate of Grade 2 lung toxicity (10\% of pneumonitis) and no Grade 3 toxicity while local control was $81 \%$ at 2 years.

John et al, recently published a retrospective multicenter $(\mathrm{n}=8)$ study focused on patients $(n=27)$ treated by two courses of lung SBRT. The reported one-year local control rate was $78.3 \%$ and no grade $>2$ toxicity was observed. However, the reported delivered doses were inferior to those of our series. In particular, the first course median dose was $38.5 \mathrm{~Gy}$ in 5 fractions while the median reported dose was $40 \mathrm{~Gy}$ in 5 fractions [10].

Hear et al reported a series of 10 patients that benefited of SBRT reirradiation with BED10 doses $\geq 100 \mathrm{~Gy}$, this treatment was considered as a viable salvage option for inoperable locally recurrent NSCLC [11]. Nishimura et al also reported the cases of two elderly patients successfully treated by salvage lung SBRT reirradiation [12]. In our experience, we performed cumulative physical dose summation to evaluate the safety of the reirradiation. Cumulative dose had to respect the most restrictive constraints template for stereotactic radiotherapy (Fig. 1). As an example, if the first course was delivered in 5 fractions and the reirradiation was delivered in 8 fractions, the composite plan had to respect the constraints of a 5 fraction plan for organs at risk according to American Association of Physicists in Medicine doses constraints [3]. Moreover, we collected data concerning MLD and V5 and tried to optimize their values, as higher values seem to be part of complications occurrence, and we did not observed any Grade 3 or more toxicity at last news $[13,14]$. We can notice that we did not treat central or ultra-central tumors directly invading bronchial tree [15]. The main limitation of the report is the low number of patients, however our results seems to correspond to the previously published data.

\section{Conclusion}

In our preliminary experience, we observed short-term favorable outcome of lung SBRT reirradiation in patients presenting isolated local relapse of an early-stage NSCLC. Further studies are necessary in order to establish if this approach could be considered a safe and effective salvage treatment.

Table 1

Patients and treatment characteristics.

\begin{tabular}{|c|c|c|c|c|c|c|c|c|c|c|c|}
\hline $\begin{array}{l}\text { Patients } \\
\text { Number }\end{array}$ & $\begin{array}{l}\text { Age } \\
\text { (years) }\end{array}$ & $\begin{array}{l}\text { Performans } \\
\text { Status }\end{array}$ & Histology & $\begin{array}{l}\text { Time to } \\
\text { relapse } \\
\text { (Months) }\end{array}$ & $\begin{array}{l}\text { First course } \\
\text { regimen }(\mathrm{Gy} / \\
\text { number of } \\
\text { fractions) }\end{array}$ & $\begin{array}{l}\text { Second course } \\
\text { regimen (Gy/ } \\
\text { number of } \\
\text { fractions) }\end{array}$ & $\begin{array}{l}\text { PTV Maximal } \\
\text { physical dose } \\
\text { summation } \\
(\mathrm{Gy})\end{array}$ & $\begin{array}{l}\text { Mean } \\
\text { Lung } \\
\text { Dose } \\
(\mathrm{Gy}) \\
\end{array}$ & $\begin{array}{l}\text { Cumulative } \\
\text { mean lung } \\
\text { dose (Gy) }\end{array}$ & $\begin{array}{l}\text { Volume of } \\
\text { Lung } \\
\text { receiving } \\
5 \mathrm{~Gy} \mathrm{( \% )} \\
\end{array}$ & $\begin{array}{l}\text { Cumulative } \\
\text { Volume of } \\
\text { Lung receiving } \\
5 \mathrm{~Gy}(\%)\end{array}$ \\
\hline $\mathrm{N}-1$ & 82,6 & 1 & SCC & 93,4 & $60 / 8$ & $60 / 8$ & 135,3 & 1,6 & 7,3 & 7,5 & 32,0 \\
\hline $\mathrm{N}-2$ & 88,8 & 2 & SCC & 31,3 & $55 / 5$ & $50 / 5$ & 90,3 & 1,9 & 5,1 & 7,3 & 28,5 \\
\hline $\mathrm{N}-3$ & 75,2 & 1 & ADK & 37,5 & $54 / 3$ & $60 / 8$ & 90,8 & 1,1 & 4,1 & 4,9 & 16,0 \\
\hline $\mathrm{N}-4$ & 78,9 & 2 & SCC & 15,6 & $45 / 3$ & $35 / 5$ & 76,2 & 2,0 & 7,8 & 9,0 & 48,5 \\
\hline N-5 & 62,6 & 1 & ADK & 21,4 & $55 / 5$ & $60 / 8$ & 101,1 & 2,0 & 3,6 & 9,5 & 19,0 \\
\hline
\end{tabular}

SCC: Squamous cell cancer.

ADK: Adenocarcinoma. 


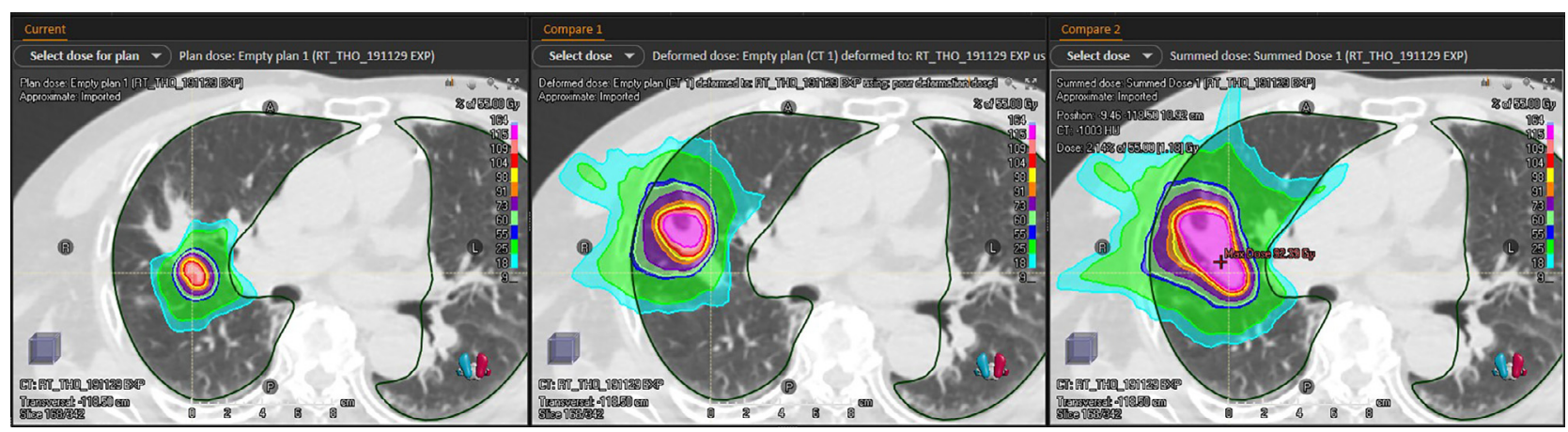

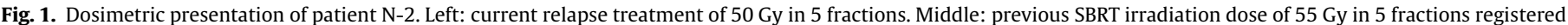
using deformable registration on current CT. Right: cumulative dosimetry of treatments with maximal point dose of 92.4 Gy.

\section{Declaration of Competing Interest}

The authors declare that they have no known competing financial interests or personal relationships that could have appeared to influence the work reported in this paper.

\section{References}

[1] Stephans KL, Woody NM, Reddy CA, Varley M, Magnelli A, Zhuang T, Qi P, Videtic GMM. Tumor control and toxicity for common stereotactic body radiation therapy dose-fractionation regimens in stage I non-small cell lung cancer. Int J Radiat Oncol Biol Phys 2018;100(2):462-9. https://doi.org/ 10.1016/i.ijrobp.2017.10.037.

[2] Tada T, Fukuda H, Matsui K, Hirashima T, Hosono M, Takada Y, Inoue Y. Nonsmall-cell lung cancer: reirradiation for loco-regional relapse previously treated with radiation therapy. Int J Clin Oncol 2005;10(4):247-50. https:// doi.org/10.1007/s10147-005-0501-1.

[3] Benedict SH, Yenice KM, Followill D, Galvin JM, Hinson W, Kavanagh B, Keall P, Lovelock M, Meeks S, Papiez L, Purdie T, Sadagopan R, Schell MC, Salter B, Schlesinger DJ, Shiu AS, Solberg T, Song DY, Stieber V, Timmerman R, Tomé WA, Verellen D, Wang Lu, Yin F-F. Stereotactic body radiation therapy: The report of AAPM Task Group 101: Stereotactic body radiation therapy: The report of TG101. Med Phys 2010;37(8):4078-101. https://doi.org/10.1118/ 1.3438081.

[4] Trotti A, Colevas AD, Setser A, et al. CTCAE v3.0: development of a comprehensive grading system for the adverse effects of cancer treatment. Semin Radiat Oncol 2003;13:176-81. https://doi.org/10.1016/S1053-4296(03) 00031-6.

[5] Kelly P, Balter PA, Rebueno N, Sharp HJ, Liao Z, Komaki R, Chang JY. Stereotactic body radiation therapy for patients with lung cancer previously treated with thoracic radiation. Int J Radiat Oncol Biol Phys 2010;78(5):1387-93. https:// doi.org/10.1016/j.ijrobp.2009.09.070.

[6] Kruser TJ, McCabe BP, Mehta MP, et al. Reirradiation for locoregionally recurrent lung cancer: Outcomes in small cell and non-small cell lung carcinoma. Am J Clin Oncol Cancer Clin Trials 2014;37:70-6. https://doi.org/ 10.1097/COC.0b013e31826b9950.

[7] McAvoy S, Ciura K, Wei C, Rineer J, Liao Z, Chang JY, Palmer MB, Cox JD, Komaki $\mathrm{R}$, Gomez DR. Definitive reirradiation for locoregionally recurrent non-small cell lung cancer with proton beam therapy or intensity modulated radiation therapy: predictors of high-grade toxicity and survival outcomes. Int J Radiat Oncol Biol Phys 2014;90(4):819-27. https://doi.org/10.1016/i. ijrobp.2014.07.030.

[8] Chao H-H, Berman AT, Simone II CB, Ciunci C, Gabriel P, Lin H, Both S, Langer C, Lelionis K, Rengan R, Hahn SM, Prabhu K, Fagundes M, Hartsell W, Mick R, Plastaras JP. Multi-institutional prospective study of reirradiation with proton beam radiotherapy for locoregionally recurrent non-small cell lung cancer. J Thorac Oncol 2017;12(2):281-92. https://doi.org/10.1016/i.jtho.2016.10.018.

[9] Sumodhee S, Bondiau P-Y, Poudenx M, Cohen C, Naghavi AO, Padovani B, Maneval D, Gal J, Leysalle A, Ghalloussi H, Otto J, Doyen J. Long term efficacy and toxicity after stereotactic ablative reirradiation in locally relapsed stage III non-small cell lung cancer. BMC Cancer 2019;19(1). https://doi.org/10.1186/ s12885-019-5542-3.

[10] John C, Dal Bello R, Andratschke N, Guckenberger M, Boda-Heggemann J, Gkika E, Mantel F, Specht HM, Stromberger C, Zehentmayr F, Blanck O, Balermpas P. In-field stereotactic body radiotherapy (SBRT) reirradiation for pulmonary malignancies as a multicentre analysis of the German Society of Radiation Oncology (DEGRO). Sci Rep 2021;11(1). https://doi.org/10.1038/s41598-02183210-3.

[11] Hearn JWD, Videtic GMM, Djemil T, Stephans KL. Salvage stereotactic body radiation therapy (SBRT) for local failure after primary lung SBRT. Int J Radiat Oncol Biol Phys 2014;90(2):402-6. https://doi.org/10.1016/i. ijrobp.2014.05.048.

[12] Nishimura S, Takeda A, Sanuki N, Yoshida S, Shigematsu N. Dose-escalated stereotactic body radiotherapy (SBRT) as a salvage treatment for two cases with relapsed peripheral lung cancer after initial SBRT. J Thorac Oncol 2015;10 (8):e69-71. https://doi.org/10.1097/[T0.0000000000000543.

[13] Dupic G, Biau J, Molnar I, et al. Significant correlation between overall survival and mean lung dose in lung stereotactic body radiation therapy (SBRT). Front Oncol 2020;10. https://doi.org/10.3389/fonc.2020.01577.

[14] Amini A, Yeh N, Gaspar LE, Kavanagh B, Karam SD. Stereotactic body radiation therapy (SBRT) for lung cancer patients previously treated with conventional radiotherapy: a review. Radiat Oncol 2014;9(1):210. https://doi.org/10.1186/ 1748-717X-9-210.

[15] Chaudhuri AA, Tang C, Binkley MS, Jin M, Wynne JF, von Eyben R, Hara WY, Trakul N, Loo Jr BW, Diehn M. Stereotactic ablative radiotherapy (SABR) for treatment of central and ultra-central lung tumors. Lung Cancer 2015;89 (1):50-6. https://doi.org/10.1016/j.lungcan.2015.04.014. 